\title{
Size control of Au nanoparticles from the scalable and solvent-free matrix assembly cluster source
}

\author{
Maria Chiara Spadaro 1 Lu Cao • William Terry • \\ Richard Balog • Feng Yin • Richard E. Palmer
}

Received: 15 January 2020 / Accepted: 29 April 2020 /Published online: 23 May 2020

(C) The Author(s) 2020

\begin{abstract}
Nanostructured gold is an intriguing system for heterogeneous catalysis at low temperature. Its activity is related to choice of support selection, particle-support interaction, and especially the particle size. Here, we investigate the possibility of controlling the size of Au clusters (nanoparticles) in the novel Matrix Assembly Cluster Source (MACS), a solvent-free nanoparticle source with potential for scale-up to the gram level. The novelty of the MACS is the idea of making clusters by sputtering a precondensed matrix of metal atoms embedded in a condensed non-reactive gas, e.g., Ar. This concept, introduced in 2016, has already proved deposition rates several orders of magnitude higher than conventional cluster beam routes. Such scale-up in the cluster production rate is crucial for industrial research on nanocatalysis under realistic reaction condition. Here, we report a systematic study
\end{abstract}

\footnotetext{
M. C. Spadaro $(\bowtie) \cdot$ R. E. Palmer $(\bowtie)$

College of Engineering, Bay Campus, Swansea University, Fabian Way, Swansea SA1 8EN, UK

e-mail: mariachiara.spadaro@icn2.cat

e-mail: r.e.palmer@swansea.ac.uk

L. Cao $\cdot$ W. Terry

Nanoscale Physics Research Laboratory, School of Physics and Astronomy, University of Birmingham, B152TT, Birmingham, UK

R. Balog

Department of Physics and Astronomy, Aarhus University, Ny Munkegade 120, 8000 Aarhus C, Denmark

F. Yin

School of Physics and Information Technology, Shaanxi Normal University, Xi'an 710062, China
}

of how $\mathrm{Au}$ metal loading in the matrix affects the size distribution of clusters generated. Furthermore, the obtained dependence of cluster size on deposition time provides clear confirmation of cluster formation inside the matrix by ion irradiation, rather than by aggregation of atoms on the TEM support after deposition.

Keywords Nanoparticle · Solvent-free synthesis · Scaleup production - Cluster - Gold - Size dependence .

Catalysis · Gas phase aggregation

\section{Introduction}

The present work is motivated by the fact that the active sites in heterogeneous catalysis are frequently supported nanoparticles. Moreover, by decreasing the nanoparticle size down to $1 \mathrm{~nm}, 90 \%$ of the atoms of the particle are located at the surface and thus available to catalyze a reaction (Piella et al. 2017). The effect of size on reactivity has been investigated for many different systems, both metals and oxides, including $\mathrm{Cu}$ (Reske et al. 2014; Fernandez et al. 2015), Ag (Boronat et al. 2014), Ru (Antares Paoli et al. 2016), Pt (Perez-Alonso et al. 2012), $\mathrm{Pd}$ (Chen et al. 2012), and $\mathrm{CeO}_{2-\mathrm{x}}$ (Sun and Xue 2013, Spadaro et al. 2015, D’Addato and Spadaro 2018). In the case of gold, it was reported in 1987 that this noble metal became catalytically active only when its size is below $5 \mathrm{~nm}$ (Masatake et al. 1987; Ishida et al. 2019). Many subsequent experiments investigated $\mathrm{Au}$ in its nanostructured form (Valden and Goodman 1998, Boyen et al. 2002). To give just one example, direct comparison 
between $\mathrm{Au}$ films and micelle-encapsulated nanoparticles with size below $5 \mathrm{~nm}$ (deposited on ITO-coated glass) evidenced activity for $\mathrm{CO}$ electro-oxidation by the nanoparticles (Jaramillo et al. 2003), where higher activity was found for $1.5 \mathrm{~nm}$ clusters than $4 \mathrm{~nm}$ or $6 \mathrm{~nm}$ ones (Roldan Cuenya et al. 2003). The literature shows that the gold nanoparticle preparation method also strongly affects the reactivity; therefore, the possibility to investigate model gold systems whose characteristics can be tuned independently of interaction with the support is desirable. Among the available techniques which generate "pre-prepared" nanoparticles, cluster beam deposition is an emerging technology able to produce films of clusters with tunable size and composition (Palmer et al. 2018; Grammatikopoulos et al. 2016; Ayodele et al. 2020). Moreover, since it does not need solvent for the generation and stabilization of the nanoparticles, it obeys the green chemistry 12 principles (Anastas and Warner 1998) and thus represents an appealing new method of preparation of model catalysts.

Extensive investigations of the catalytic activity of deposited Au clusters have explored the dependence on the size (Hvolbæk et al. 2007) and on the cluster-support interaction. For example, in the work of Anderson et al. (Lee et al. 2004, 2005), CO oxidation on model Au catalysts in a UHV system on $\mathrm{Al}_{2} \mathrm{O}_{3}$ was investigated, observing that both $\mathrm{CO}$ binding and oxidation depended on the cluster size as well as the support nature. The clusters were produced by laser vaporization of gold into flowing helium. No catalytic activity was detected for $\mathrm{Au} / \mathrm{Al}_{2} \mathrm{O}_{3}$, whereas for $\mathrm{Au} / \mathrm{TiO}{ }_{2}$, the activity was notable and attributed to the reduced number of defect on the support. For $\mathrm{Au} / \mathrm{Al}_{2} \mathrm{O}_{3}$, strong sintering was observed, due also to the absence of defects on the surface: electron-rich oxygen vacancies strongly bind $\mathrm{Au}$, stabilizing the system. Alloying Au with other metals, such as $\mathrm{Ti}$, can also increase the cluster-support interaction strength (Niu et al. 2018).

A crucial challenge for the solvent-free cluster deposition approach to match Au-based catalysts is the deposition rate, as it is conventionally limited to $\sim \mu g / h$ of metal (Pratontep et al. 2005). Industrial results under realistic reaction conditions demand typically $\sim m g / h o u r$, and for manufacturing, rates of $\sim g /$ hour of clusters will be needed. The Matrix Assembly Cluster Source (MACS) addresses this issue of production rate (Palmer et al. 2016) and is based on a new principle for the generation of clusters: ion beam impact on a matrix of metal atoms in a non-reactive gas condensed on a cryogenically cooled support. Demonstration experiments have employed either $\mathrm{Ar}$ (Zhao et al. 2017) or $\mathrm{CO}_{2}$ (Oiko et al. 2016) as the matrix gas.
Clusters generated by the MACS have already been tested in the oxygen evolution reaction (OER) experiments (Co clusters) (Xu et al. 2018) and the vapor phase selective hydrogenation of 1-pentyne to 1-pentene ( $\mathrm{Pd}$ and $\mathrm{Pd} / \mathrm{Au}$ clusters) (Palmer et al. 2018), demonstrating the production potential of this new type of cluster source. In recent papers, the cluster formation and emission mechanisms were investigated in detail, optimizing the deposition rates (Spadaro et al. 2019; Zhao et al. 2017; Ellis et al. 2016). The resulting cluster flux is also strongly connected with the ion beam sputtering geometry. At grazing incidence with respect to the matrix support, the primary energy from the $\mathrm{Ar}^{+}$ions is released within the surface region, leading to efficient matrix sublimation around embedded clusters, which are consequently emitted and collected (Spadaro et al. 2019). Here, we report on the size of ( $\mathrm{Au}$ ) clusters produced by the MACS when exploiting such grazing ion beam incidence condition. Specifically, the cluster size is shown to be controlled by the degree of metal loading in the matrix. We also prove that cluster formation takes place in the matrix and is not due to simple metal aggregation on the TEM support after deposition.

\section{Experimental method}

The MACS was operated in "transmission mode," allowing $\mathrm{Ar}^{+}$ions to sputter the matrix at grazing incidence. The set-up of the source is shown elsewhere (Palmer et al. 2016). The matrix support is a $\mathrm{Cu} 1000$ mesh grid, as $\mathrm{Cu}$ is characterized by good thermal conductivity and robustness. The support was cooled down by a continuous flow of liquid helium $(\mathrm{T}<15 \mathrm{~K})$. The vacuum chamber (base pressure $10^{-8} \mathrm{mbar}$ ) is filled with $\mathrm{Ar}(>$ $10^{-7} \mathrm{mbar}$ ), and at the same time, the metal of interest ( $\mathrm{Au}$ or $\mathrm{Ag}$ ) is evaporated onto the matrix support grid. For the experiments reported here, the chamber was filled with inert gas (Ar) at a pressure of $\sim 10^{-6}$ mbar using a leak valve, leading to an Ar-matrix with embedded metal atoms. The metal deposition rate in the matrix was monitored by a quartz crystal microbalance placed adjacent to the support, facing the metal evaporator. The temperature of $\mathrm{Cu}$ mesh during the matrix formation was $9 \mathrm{~K}$. Clusters are produced by subsequent high-energy $\mathrm{Ar}$ ion beam impact on the matrix; the ion beam energy used to sputter the matrix was $1 \mathrm{keV}$ with an Ar beam current of $50 \mu \mathrm{A}$.

The clusters were deposited onto TEM grids, and the cluster size distribution was obtained by analyzing highangular annular dark-field (HAADF) images from a probe- 
corrected scanning transmission electron (STEM) microscope (JEOL 2100F, with a CEOS spherical aberration corrector). The HAADF images were acquired with inner and outer collection angles of $62 \mathrm{mrad}$ and $164 \mathrm{mrad}$ (camera length $10 \mathrm{~cm}$ ).

\section{Results and discussion}

The morphology of the clusters was investigated with probe-corrected HAADF STEM. The size of the clusters was derived through atom counting method, using as reference the HAADF-STEM intensity of size-selected $\mathrm{Au}_{923}$ clusters, prepared using a magnetron sputtering cluster source (von Issendorff and Palmer 1999) with mass resolution of $\pm 2.5 \%$. The linear dependence of cluster intensity (after background subtraction) on cluster nuclearity is demonstrated in Wang et al. (2011) and Wang and Palmer (2012).

First of all, we demonstrate how the size of the clusters created in the matrix can be controlled by varying the metal loading in the matrix, that is, the ratio of metal atoms to Ar atoms. In Fig. 1 are shown the HAADF STEM images of Au clusters deposited from the MACS with four different matrix concentrations.

The deposition time was $120 \mathrm{~s}$ for all the depositions, while the matrix temperature was kept again at $9 \mathrm{~K}$. It is clear from Fig. 1 that the number of deposited clusters decreases when the metal loading increases, while at the
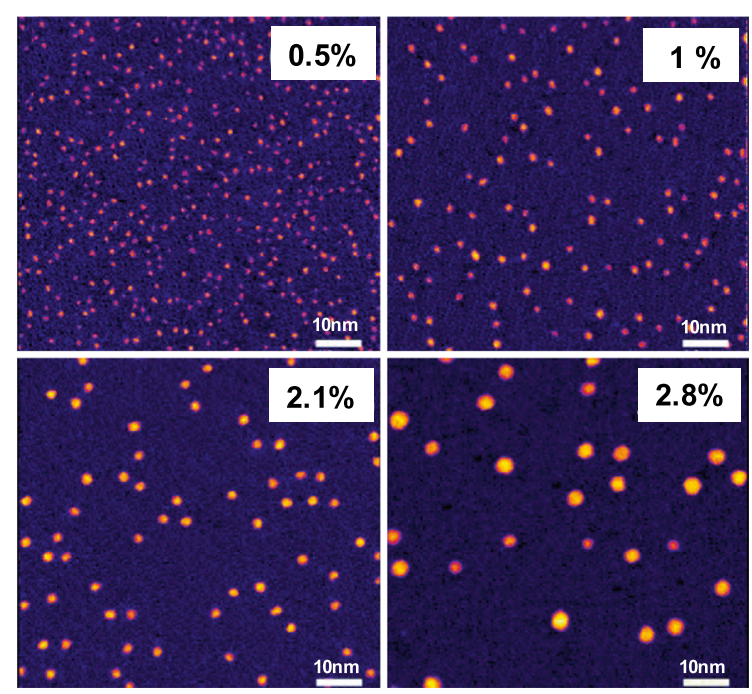

Fig. 1 HAADF-STEM images of Au clusters prepared with different metal concentrations in the MACS matrix from 0.5 to $2.8 \%$. The scale bars correspond to $10 \mathrm{~nm}$
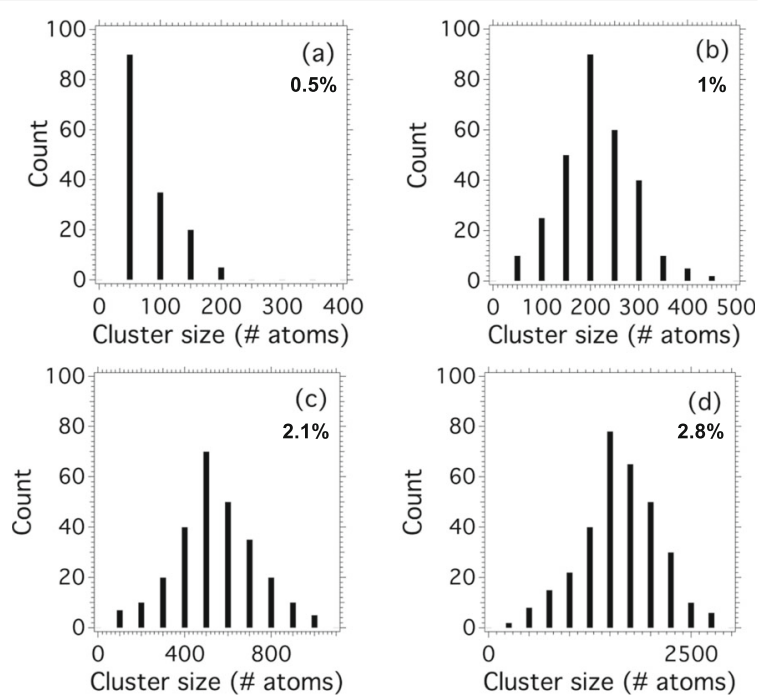

Fig. 2 Histograms of the size of deposited Au clusters for different metal loadings in the MACS matrix, from 0.5 to $2.8 \%$

same time, the cluster size increases. The corresponding histograms of size distribution are shown in Fig. 2.

The peak in the cluster size distribution, Fig. 2, shifts from 50 to 200,500 , and 1500 atoms/cluster (corresponding to cluster size of less than $1 \mathrm{~nm}, 2 \mathrm{~nm}, 3 \mathrm{~nm}$, and $4 \mathrm{~nm}$, respectively) for metal loadings of $0.5,1,2.1$, and 2.8 at. \%, respectively. As the Au concentration in the matrix increases, the cluster size distribution also becomes somewhat broader.

This cluster size and cluster deposition rate are plotted in Fig. 3 as a function of metal loading.

The trends observed in Figs. 2 and 3 are similar to the behavior of $\mathrm{Ag}$ clusters generated by the MACS with the same sputtering geometry and
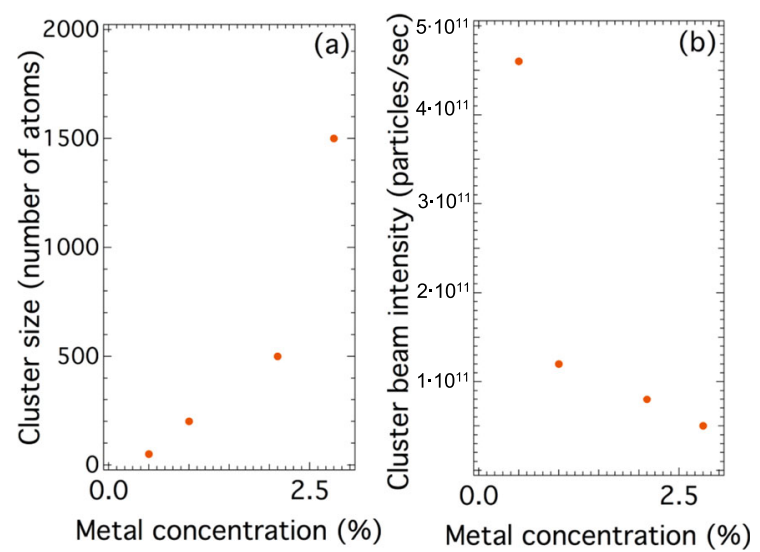

Fig. 3 a Plot of the cluster size and $\mathbf{b}$ the cluster deposition rate as a function of metal concentration in the matrix 
similar matrix conditions (Zhao et al. 2017). For both metals, i.e., $\mathrm{Au}$ and $\mathrm{Ag}$, the cluster size is strongly influenced by the matrix metal concentration. A monotonic increase in cluster size is observed as the metal loading in the matrix increases while the cluster deposition rate (particles/s) decreases. The similar tendency in generation of $\mathrm{Au}$ and Ag clusters (Zhao et al. 2017) is satisfying because it demonstrates the universality of the MACS method for the production of clusters with different materials but also its ability to control the cluster size, obtained in the sub-5 nm regime, with matrix loadings. The absolute rate of cluster deposition can at the same time be controlled by other MACS parameters, notably the ion beam sputtering current and energy (Spadaro et al. 2019).

Finally, a critic of the cluster beam deposition method may ask "How can you be sure the clusters are formed prior to deposition and not by aggregation of atoms on the support"?

Figure 4 is set out to show that the clusters analyzed in the HAADF-STEM were indeed formed inside the matrix prior to deposition on the TEM grid, as also indicated theoretically (Spadaro et al. 2019; Zhao et al. 2017). HAADF STEM images were acquired from a series of cluster samples deposited for different times. In this case, the cluster material was Ag, which is our standard test material (Spadaro et al. 2019; Zhao et al. 2017; Oiko et al. 2016; Cai et al. 2020). Figure 4 shows HAADF-STEM images and corresponding size distributions after deposition of clusters for $60 \mathrm{~s}$ and $5 \mathrm{~min}$, while keeping
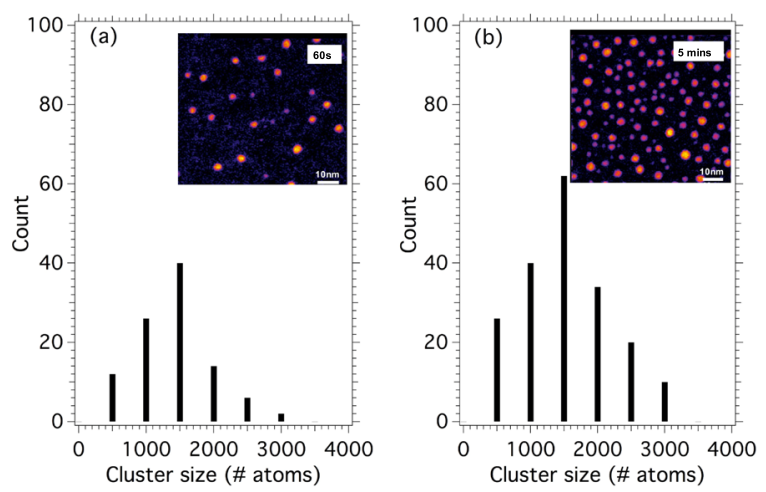

Fig. 4 Histograms and corresponding HAADF-STEM images of $\mathrm{Ag}$ clusters prepared at matrix metal concentration of $3.2 \%$ with different deposition times, $\mathbf{a} 60 \mathrm{~s}$ and $\mathbf{b} 5 \mathrm{~min}$. The scale bar in the HAADF-STEM images corresponds to $10 \mathrm{~nm}$ the matrix temperature at $9 \mathrm{~K}$. If the clusters were formed by aggregation of atoms deposited on the TEM film, then their size distribution would be expected to change substantially with increasing deposition time.

However, the cluster size distributions in Fig. 4 a and $\mathrm{b}$ are very similar. In both graphs, the distribution peaks at around 1500 atoms/cluster. In fact, the tail of the distribution at large size grows slightly as the deposition time increases, but this is attributed to clusters landing on top of each other with increasing cluster density on the support. This consistent size distribution confirms that the clusters emerge from the matrix before landing on the surface.

\section{Conclusions}

Several of our papers clearly demonstrate the scale-up of the MACS deposition rate toward and beyond the $\mathrm{mg} / \mathrm{h}$ level. In this paper, we show that the size of $\mathrm{Au}$ clusters generated by the MACS can be tuned by the metal concentration in the MACS matrix. Cluster sizes ranging between 50 and 1500 atoms $(0.9-4 \mathrm{~nm})$ are obtained for a metal loading range of $0.5-2.8$ at. $\%$. The results confirm the type of behavior originally observed for $\mathrm{Ag}$ clusters and demonstrate the universality of the MACS method for solvent-free production of metal nanoparticles below $5 \mathrm{~nm}$ in size for catalysis studies, including specifically the topical $\mathrm{Au}$ system. Furthermore, we confirmed, by cluster deposition for different durations, that the cluster is not formed by atomic diffusion on the TEM support but in the MACS matrix itself. The method should allow the precise deposition of various clusters, both elemental and alloy, on different types of support, both planar and powder, for diverse catalytic studies with cluster deposition rate in the $\mathrm{mg}$ to the gram per hour scale. The next step will be the investigation of alloyed or core-shell nanoparticles by loading the matrix with different metals.

Funding information We thank the EPSRC, the Leverhulme Trust, Innovate UK, and the EU H2020 project CritCat (project ID: 686053) for their financial support. The MACS concept is the subject of the following patent applications: Palmer, R. E.; PCT Patent Application No. WO2013017870; Europe Patent 
Application No. EP2739565; China Patent Application No. CN103857618; Japan Patent Application No. JP6316748; and US Patent Application No. US10233545.

\section{Compliance with ethical standards}

Conflict of interest The authors declare that they have no conflicts of interest.

Open Access This article is licensed under a Creative Commons Attribution 4.0 International License, which permits use, sharing, adaptation, distribution and reproduction in any medium or format, as long as you give appropriate credit to the original author(s) and the source, provide a link to the Creative Commons licence, and indicate if changes were made. The images or other third party material in this article are included in the article's Creative Commons licence, unless indicated otherwise in a credit line to the material. If material is not included in the article's Creative Commons licence and your intended use is not permitted by statutory regulation or exceeds the permitted use, you will need to obtain permission directly from the copyright holder. To view a copy of this licence, visit http://creativecommons.org/licenses/by/4.0/.

\section{References}

Anastas PT, Warner JC (1998) Green chemistry: theory and practice. Oxford University Press, p 30

Antares Paoli E, Masini F, Frydendal R, Deiana D, Malacrida P, Hansen TW, Chorkendorff I, Stephens IEL (2016) Finetuning the activity of oxygen evolution catalysts: the effect of oxidation pre-treatment on size-selected Ru nanoparticles. Catal Today 262:57-64. https://doi.org/10.1016/j. cattod.2015.10.005

Ayodele OB, Cai R, Wang J, Ziouani Y, Liang Z, Spadaro MC, Kovnir K, Arbiol J, Akola J, Palmer RE, Kolen'ko YV (2020) Synergistic computational-experimental discovery of highly selective $\mathrm{PtCu}$ nanocluster catalysts for acetylene semihydrogenation. ACS Catal 10(1):451-457. https://doi. org/10.1021/acscatal.9b03539

Boronat M, Pulido A, Concepcion P, Corma A (2014) Propene epoxidation with $\mathrm{O} 2$ or $\mathrm{H} 2-\mathrm{O} 2$ mixtures over silver catalysts: theoretical insights into the role of the particle size. Phys Chem Chem Phys 16:26600-26612. https://doi.org/10.1039 /C4CP02198C

Boyen H-G, Kastle G, Weigl F, Koslowski B, Dietrich C, Ziemann P, Spatz JP, Riethmuller S, Hartmann C, Moller M, Schimd G, Garnier MG, Oelhafen P (2002) Oxidationresistant gold-55 clusters. Science 297(5586):1533-1536. https://doi.org/10.1126/science.1076248

Cai R, Cao L, Griffin R, Chansai S, Hardacre C, Palmer RE (2020) Scale-up of cluster beam deposition to the gram scale with the matrix assembly cluster source for heterogeneous catalysis (propylene combustion). AIP Adv 10:025314. https://doi. org/10.1063/1.5142836
Chen Y-C, Lavacchi A, Chen S-P, di Benedetto F, Bevilacqua M, Bianchini C, Fornasiero P, Innocenti M, Marelli M, Oberhauser W, Sun S-G, Vizza F (2012) Electrochemical milling and faceting: size reduction and catalytic activation of palladium nanoparticles. Angew Chem Int Ed 51(34):85008504. https://doi.org/10.1002/anie.201203589

D'Addato S, Spadaro MC (2018) Low pressure bottom-up synthesis of metal@oxide and oxide nanoparticles: control of structural and functional properties. Phys Scr 93(3):033001. https://doi.org/10.1088/1402-4896/aa9db7

Ellis P, Brown CM, Bishop PT, Y in J, Cooke K, Terry WD, Liu J, Yin F, Palmer RE (2016) The cluster beam route to model catalysts and beyond. Faraday Discuss 188:39-56. https://doi.org/10.1039/C5FD00178A

Fernandez E, Boronat M, Corma A (2015) Trends in the reactivity of molecular $\mathrm{O} 2$ with copper clusters: influence of size and shape. J Phys Chem C 119(34):19832-19846. https://doi. org/10.1021/acs.jpcc.5b05023

Grammatikopoulos P, Steinhauer S, Vernieres J, Singh V, Sowwan M (2016) Nanoparticle design by gas-phase synthesis. Advan Phys 1(1):81-100. https://doi.org/10.1080 /23746149.2016.1142829

Hvolbæk B, Janssens TVW, Clausen BS, Falsig H, Christensen CH, Nørskov JK (2007) Catalytic activity of Au nanoparticles. Nano Today 2:14-18. https://doi.org/10.1016/S17480132(07)70113-5

Ishida T, Murayama T, Taketoshi A, Haruta M (2019) Importance of size and contact structure of gold nanoparticles for the genesis of unique catalytic processes. Chem Rev. https://doi. org/10.1021/acs.chemrev.9b00551

Jaramillo TF, Baeck S-H, Cuenya Roldan B, McFarland EW (2003) Catalytic activity of supported Au nanoparticles deposited from block copolymer micelles. J Am Chem Soc 125(24):7148-7149. https://doi.org/10.1021/ja029800v

Lee S, Fan C, Wu T, Anderson SL (2004) CO oxidation on Au/ $\mathrm{TiO} 2$ catalysts produced by size selected cluster deposition. $\mathrm{J}$ Am Chem Soc 126:5682-5683. https://doi.org/10.1021 /ja049436v

Lee S, Fan C, Wu T, Anderson SL (2005) Agglomeration, sputtering and carbon monoxide adsorption behavior for $\mathrm{Au} / \mathrm{A} 12 \mathrm{O} 3$ prepared by Aun+ deposition on A12O3/ NiAl(110). J Phys Chem B 109:11340-11347. https://doi. org/10.1021/jp0502407

Masatake H, Tetsuhiko K, Hiroshi S, Nobumasa Y (1987) Novel gold catalysts fir the oxidation of carbon monoxide at a temperature far below $0{ }^{\circ} \mathrm{C}$. Chem Lett 16(2):405-408. https://doi.org/10.1246/cl.1987.405

Niu Y, Schexer P, Sebok B, Chorkendorff I, Palmer RE (2018) Reduced sintering of mass-selected Au clusters on $\mathrm{SiO} 2$ by alloying with Ti: an aberration-corrected STEM and computation study. Nanoscale 10(5):2363-2370. https://doi. org/10.1039/C7NR06323G

Oiko VTA, Mathieu T, Cao L, Liu J, Palmer RE (2016) Note: production of silver nanoclusters using a Matrix-Assembly Cluster Source with a solid CO2 matrix. J Chem Phys 145: 166101. https://doi.org/10.1063/1.4966213

Palmer RE, Cao L, Yin F (2016) Note: proof of principle of a new type of cluster beam source with potential scale-up. Rev Sci Instrum 87:046103. https://doi.org/10.1063/1.4947229

Palmer RE, Cai R, Vernieres J (2018) Synthesis without solvents: the cluster (nanoparticle) beam route to catalysts and sensors. 
Acc Chem Res 51(9):2296-2304. https://doi.org/10.1021 /acs.accounts.8b00287

Perez-Alonso FJ, McCarthy DN, Nierhoff A, HernandezFernandez P, Strebel C, Stephens IEL, Nielsen JH, Cherkendorff I (2012) The effect of size on the oxygen electroreduction activity of mass-selected platinum nanoparticles. Angew Chem Int Ed 51:4641-4643. https://doi. org/10.1002/anie.201200586

Piella J, Merkoci F, Genc A, Arbiol J, Bastus NG, Puntes V (2017) Probing the surface reactivity of nanocrystals by the catalytic degradation of organic dyes: the effect of size, surface chemistry and composition. J Mater Chem A 5:11917-11929. https://doi.org/10.1039/c7ta01328k

Pratontep S, Carroll SJ, Xirouchaki C, Streun M, Palmer RE (2005) Size-selected cluster beam source based on radio frequency magnetron plasma sputtering and gas condensation. Rev Sci Instrum 76:045103. https://doi.org/10.1063 $/ 1.1869332$

Reske R, Mistry H, Behafarid F, Roldan Cuenya B, Strasser P (2014) Particle size effects in the catalytic electroreduction of CO2 on Cu nanoparticles. J Am Chem Soc 136(19):69786986. https://doi.org/10.1021/ja500328k

Roldan Cuenya B, Baeck S-H, Jaradillo TF, McFarland EW (2003) Size- and support-dependent electronic and catalytic properties of $\mathrm{Au} 0 / \mathrm{Au} 3+$ nanoparticles synthesized from block copolymer micelles. J Am Chem Soc 125(42): 12928-12934. https://doi.org/10.1021/ja036468u

Spadaro MC, D'Addato S, Gasperi G, Benedetti F, Luches P, Grillo V, Bertoni G, Valeri S (2015) Morphology, structural properties and reducibility of size-selected $\mathrm{CeO} 2-\mathrm{x}$ nanoparticle films. Beilstein J Nanotechnol 6(1):60-67. https://doi. org/10.3762/bjnano.6.7

Spadaro MC, Zhao J, Terry WD, Liu J, Yin F, Djurabekova F, Palmer RE (2019) Angular dependence of nanoparticle generation in the matrix assembly cluster source. Nano Res
12(12):3069-3074. https://doi.org/10.1007/s12274-0192553-y

Sun C, Xue D (2013) Size-dependent oxygen storage ability of nano-sized ceria. Phys Chem Chem Phys 15:14414-14419. https://doi.org/10.1039/C3CP51959G

Valden M, Goodman DW (1998) Onset of Catalytic activity of gold clusters on titania with the appearance of non-metallic properties. Science 281(5383):1647-1650. https://doi. org/10.1126/science.281.5383.1647

von Issendorff B, Palmer RE (1999) A new high transmission infinite range mass selector for cluster and nanoparticle beams. Rev Sci Instrum 70:4497-4501. https://doi. org/10.1063/1.1150102

Wang ZW, Palmer RE (2012) Intensity calibration and atomic imaging of size selected $\mathrm{Au}$ and Pd clusters in aberration corrected HAADF-STEM. J Phys Conf Ser 371:012010. https://doi.org/10.1088/1742-6596/371/1/012010

Wang ZW, Li ZY, Park SJ, Abdela A, Tang D, Palmer RE (2011) Quantitative Z-contrast imaging in the scanning transmission electron microscope with size-selected clusters. Phys Rev B 84:073408. https://doi.org/10.1103/PhysRevB.84.073408

Xu J, Murphy S, Xiong D, Cai R, Wei XK, Heggen M, Barborini E, Vinati S, Dunin-Borkowski R, Palmer RE, Liu L (2018) Cluster beam deposition of ultrafine cobalt and ruthenium clusters for efficient and stable oxygen evolution reaction. ACS Appl En Mater 1:3013-3018. https://doi.org/10.1021 /acsaem.8b00111

Zhao J, Cao L, Palmer RE, Nordlund K, Djurabekova F (2017) Formation and emission mechanisms of Ag nanoclusters in the Ar matrix assembly cluster source. Phys Rev Mater 1: 066002. https://doi.org/10.1103/PhysRevMaterials.1.066002

Publisher's note Springer Nature remains neutral with regard to jurisdictional claims in published maps and institutional affiliations. 